\title{
BREVE COMPENDIO DE GRAMMATICA PORTUGUEZA - Frei Joaquim do Amor Divino Caneca
}

\author{
Leonor Lopes Fávero*
}

RESUMO: Esta gramática, desconhecida hoje, insere-se no conjunto das gramáticas filosóficas publicadas no Brasil na primeira metade do século XIX. Tem o mérito de ter sido uma das primeiras, senão a primeira, gramática pedagógica escrita por um brasileiro.

Palavras-chave: história das idéias linguiísticas, gramática geral e filosófica, gramática pedagógica.

\section{O AUTOR}

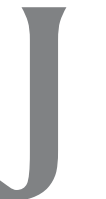

oaquim do Amor Divino Rabelo, Frei Caneca, nasceu em Recife em 1779. Era filho de um tanoeiro, por isso o apelido de Caneca. Frequientou o Seminário de Olinda, foco de idéias liberais, e entrou para a Ordem do Carmo em 1795. Foi ordenado padre em 1799. Formado em retórica e geometria, lecionou essas matérias, poética e filosofia racional e moral. Participou das atividades da Academia do Paraíso, onde se tramou a revolução de 1817. Segundo autores, redigiu o conjunto de leis da breve república pernambucana. Com a derrota, foi preso e enviado para a Bahia. Na prisão deu aulas de geometria e cálculo para seus companheiros e escreveu a gramática, aqui examinada.

Libertado em 1821, retomou suas atividades políticas em Pernambuco ${ }^{1}$.

Universidade de São Paulo

1 Faço aqui apenas algumas incursões neste terreno, já que não se trata de examinar o pensamento político de Frei Caneca. Para um estudo pormenorizado, leiam-se os 
FÁVERO, Leonor Lopes. Breve compendio de grammatica portugueza - Frei Joaquim do Amor Divino Caneca.

"Em 1817, o absolutismo, derrotando a efêmera e frágil república nordestina, reafirmara seu poder pela condenação à morte de vários de seus líderes, além da prisão e do processo de centenas de seus participantes. Em 1821, as prisões foram abertas, os condenados anistiados e os processos suspensos. Na experiência pessoal de Frei Caneca, tal fato significava que o absolutismo o trancafiara e que o movimento constitucionalista o libertara e, mais ainda, criara as condições para o exercício da atividade política de forma absolutamente nova, até então insuspeitada para o Reino Unido". (Bernardes, 1997, p. 156)

Em 1822, fez o sermão do Te Deum para comemorar a Independência, onde aparece claramente sua adesão ao governo constitucional:

"Quer fosse a propensão, que o homem herdou da natureza, para procurar outro homem e viver em sociedade, evitando as incomodidades e o enojo da solidão (24\%); quer uma encadeação necessária das coisas dimanada do amor conjugal entre estes e seus filhos (25*); quer fossem as necessidades da vida, e o desejo de fazê-la cômoda e agradável (26*); quer a prudência de por-se a coberto dos males, que se podiam temer dos outros homens (27*); quer finalmente outras causas, que ainda não lembraram aos filósofos e publicistas, o que obrigou aos primeiros pais de famílias a renunciarem a independência do estado natural, e irem formar as sociedades civis; estabelecidas estas, não se dirigem a outro fim, que o bem da espécie humana, sua existência cômoda e feliz, o aumento e perfeição de suas faculdades físicas e morais.

Eis porque a salvação do povo é a primeira máxima das leis; a fonte, de onde se derivam todas as outras; e o ponto de apoio, que sustenta os movimentos e equilibra a marcha de toda a máquina política. A este fim se instituíram os governos, que vigiassem, sobre o bem dos povos no interior das cidades, e fora delas repulsassem os males, que lhes procurava a ambição dos conquistadores, e outros opressores injustos. Por isso, com a maior sabedoria disse o grande Platão: "que o povo não foi feito para bem de quem o governa, sim os governantes foram instituídos para

trabalhos de C. G. Mota, Nordeste 1817: estruturas e argumentos, São Paulo, Perspectiva/Edusp, 1972; G. L. Leite, Estrutura e comportamentos sociais: Pernambuco em 1817, USP, 1976, tese de doutoramento e D. A. de M. Bernardes, "Pacto social e constitucionalismo em frei Caneca”, 1997, Revista de Estudos Avançados, vol. II (29), USP, p. 155-68. 
bem do povo', non populus causa gubernatoris, sed gubernator causa populi fit (28*).

Este fim, santo e augusto, é o que tem conduzido os homens a estabelecerem as diversas formas, já símplices, já compostas, do governo, que se tem visto no mundo desde o berço do gênero humano."

Note-se, porém, que o nome de Frei Caneca não se encontra entre os das quarenta e seis pessoas que subscreveram a ata do dia oito de dezembro, embora, no mesmo dia, tivesse sido o orador na cerimônia oficial do Te Deum.

\begin{abstract}
“Recusa significativa. É que, para ele, a Aclamação não poderia preceder ao ordenamento constitucional da Nação. Daí sua marcada desconfiança face ao Ministério, sua suspeita constante sobre os limites do liberalismo dos que conduziam o processo no Rio de Janeiro e a crítica vigilante a tudo quanto se publicava em torno da futura constituição." (Bernardes, idem, p. 161)
\end{abstract}

No ano seguinte, a 25 de dezembro, publicou o primeiro número de seu jornal, o Typhis Pernambucano, em que difundiu idéias liberais e criticou D. Pedro por ter dissolvido a Assembléia Constituinte no Rio, transcrevendo, inclusive, os decretos de dissolução da Assembléia (12 de novembro) e a Proclamação do Imperador aos brasileiros (ele estava certo em suas desconfianças).

Frei Caneca era coerente; tanto que a 6 de junho de 1824, em sessão pública, recusa-se a votar a favor da Constituição.

\footnotetext{
"O Frei Caneca que, em 6 de junho de 1824, às vésperas da Confederação do Equador, se recusou a jurar o projeto de Constituição apresentado pelo Imperador, é o mesmo do sermão da Aclamação, de 8 de dezembro
}

2 A citação foi extraída de Bernardes, op. cit., p. 157 e as notas marcadas com * são do próprio frei Caneca e assim aparecem no texto:

(424*) Puffendorf, Le droit de la nat. e des gens, liv. 2, cap. 3, parágrafo 15.

(25*) Idem, ibidem, lib. 7, cap. I, parágrafo 5.

(26*) Idem, ibidem, parágrafo 6. 
FÁVERO, Leonor Lopes. Breve compendio de grammatica portugueza - Frei Joaquim do Amor Divino Caneca.

de 1822 (...) O voto lido contra a aprovação da Constituição é o sermão da Aclamação, desenvolvido em todas as suas consequiências.” (Bernardes, idem, p. 159)

\section{Cito aqui trechos de seu voto: ${ }^{3}$}

“(...) não se deve adotar, nem jurar como constituição do império o projeto oferecido para este fim.

(...) uma constituição não é outra cousa, que a acta do pacto social, que fazem entre si os homens, quando se ajuntam e associam para viverem em reunião ou sociedade.

$$
\text { (...) }
$$

Projeto de constituição é o rascunho desta ata, que ainda há de se tirar a limpo, ou apontamentos das matérias que hão de ser ventilados no pacto (...) Portanto, o projeto oferecido por S. M. nada mais é do que o apontamento das matérias, sobre o que S. M. vai a contratar conosco. Vejamos, portanto, se a matéria aí lembrada, suas divisões e as relações destas são compatíveis com as nossas circunstâncias de independência, liberdade, integridade do nosso território, melhoramento moral e físico, e segura felicidade."

Para ele, aceitar tal documento significava a degradação "da sociedade de um povo livre e brioso, para um valongo de escravos e curral de bestas de carga”. Esta afirmação foi incluída na sentença que o condenou pela comissão encarregada de julgar os chefes da Confederação de forma "sumaríssima e verbalmente".

Segundo o mesmo Bernardes, o decreto de 26 de julho de 1824 mandou suspender o disposto no artigo 179, da Constituição que tratava da inviolabilidade dos Direitos Civis e Políticos dos Cidadãos e dizia no seu parágrafo 8: "ninguém pode ser preso sem culpa formada”.

Preso no Ceará, julgado em Recife, foi condenado à morte por enforcamento, que não ocorreu, porque o carrasco, seu ajudante, e os

(27*) Idem, ibidem, parágrafo 7. La Brenjer, car. T2, cap. 10.

(28*) Apud. L'auteur des les notion. Clair sur les gouvernemens (sic.).

3 As citações foram extraídas de Mello, ibidem. 
presos da cadeia recusaram-se a executá-lo. Morreu fuzilado no forte das Cinco Pontas em 13 de janeiro de 1825.

\section{2. $A$ OBRA}

\section{1 Visão Geral}

Escrita na prisão em Salvador, entre 1817 e 1819, para sua benfeitora, religiosa do convento do Desterro. É uma gramática pedagógica: recomendava-lhe que lesse até onde ia marcando.

Tem por objetivos:

a) ser prescritiva;

b) elucidar a natureza da linguagem.

Frei Caneca, como a maior parte dos gramáticos dos séculos XVII e XVIII, define a gramática como a arte de escrever e falar corretamente:

"Grammatica portugueza é a arte que ensina a fallar, ler e escrever correctamente a lingua portugueza." (p. 19)

Ouçamos Soares Barbosa:

"[a gramatica] não é outra coisa [...] senão a arte que ensina a pronunciar, escrever e falar correctamente qualquer lingua." (p. XI)

e, mais adiante:

"Porque a grammatica da lingua nacional é o primeiro estudo indispensável a todo homem bem criado, o qual, ainda que não aspire a outra litteratura deve ter ao menos a de fallar e escrever correctamente a sua lingua [...].” (p. XIII)

Porém, Frei Caneca afirma também: 
FÁVERO, Leonor Lopes. Breve compendio de grammatica portugueza - Frei Joaquim do Amor Divino Caneca.

"Grammatica é a arte de reduzir a regras os princípios communs a todas as linguas." (p. 20)

Como se vê aceita, embora pareça não lhe ser ainda muito clara, a divisão metodológica que Swiggers $(1984$, p. 9) considera o aspecto mais original da teoria gramatical dos enciclopedistas - a distinção entre gramática geral e particular, que se encontra em gramáticos que o precederam, como Soares Barbosa.

A obra consta de uma Introdução - onde apresenta as Ideas Geraes de Grammatica - e quatro partes: etimologia, ortografia, prosódia e sintaxe.

Na Introdução apresenta as "nove espécies de palavras" ou "as nove partes da oração": nome, artigo, pronome, verbo, particípio, advérbio, conjunção, preposição, interjeição. A divisão em quatro partes, a mesma que se encontra nos gramáticos do século anterior, como Reis Lobato e Soares Barbosa, é herança da Idade Média (talvez desde Prisciano, que foi o primeiro a reconhecer a existência de uma sintaxe que é o estudo "da disposição que visa à obtenção da oração perfeita”), com Alexandre de Villedieu (Doctrinale puerorum, 1200), divisão essa que permanece até o século XVI (Nebrija, João de Barros) ou mesmo até o século XVIII e XIX, como estamos vendo.

A divisão das "espécies de palavras" em nove remonta a Dionísio (que não inclui a interjeição) e a Prisciano (que inclui a interjeição e exclui o artigo, inexistente em latim).

\subsection{Parte - A Teoria sobre a Palavra}

\subsubsection{As partes do discurso}

Para distinguir as diferentes partes recorre a critérios, como:

a) declinabilidade - as palavras possuem ou não características morfológicas de gênero, número, pessoa, tempo e modo. Cinco são declináveis e três, indeclináveis, mais a interjeição. 
O critério de declinabilidade encontra-se também em Beauzée (Mot, E. M., vol. II, p. 571) e, segundo Swiggers (idem, p, 45):

“Le fondement de cette distinction est 'perspectiviste': les mots déclinables désignent des êtres (réels ou abstraits) qui sont susceptibles d'être envisagés sous différents aspects, alors que les mots indéclinables ne désignent que des idées qu'on ne peut envisager que sous un aspect immuable."

b) sintático-semânticos - Frei Caneca vê, seguindo Soares Barbosa, as palavras como nomeando ou combinando idéias:

"Nome é uma palavra que dá a conhecer alguma coisa, v. g.: mesa, panno."

\subsubsection{O nome}

Na Introdução, assim conceitua os nomes:

"Logo que os homens acharam os sons, isto é, as letras, cuidaram em inventar palavras para designarem os diversos objectos, que se offereciam aos seus sentidos. Como cada um destes objectos é um ser animado, ou uma substancia inanimada, as primeiras palavras, em que se conveio, foram chamadas - substantivos - isto é, nomes de substancias."

Na Etymologia reafirma ser "o nome uma palavra que dá a conhecer alguma cousa”; pode ser substantivo e adjetivo.

O substantivo "dá a conhecer a substancia da cousa" e o nome adjetivo, "a qualidade da cousa".

Tal como a Grammaire de Port-Royal, os substantivos podem ser divididos, quanto à carga extensional "do conceito de que são o signo em proprios e communs".

Quanto aos adjetivos diz serem eles "palavras para designarem os atributos e as qualidades das substancias: daí a origem dos - adjectivos - isto é, palavras que se ajuntam aos nomes para mostrar-lhes as qualidades". (p. 25) 
FÁVERO, Leonor Lopes. Breve compendio de grammatica portugueza - Frei Joaquim do Amor Divino Caneca.

Os gramáticos gregos e latinos também não os consideram uma classe à parte, mas uma subdivisão do nome; a distinção substantivo-adjetivo é devida à escolástica.

Prisciano usava o termo adjectivum, no sentido de qualificativo, porém sem considerá-lo uma classe independente; essa distinção vem da gramática medieval. Nebrija coloca o adjetivo entre os nomes, porém o conceitua de modo diferente do substantivo.

Assim diz:

"Calidad esso mesmo en el nombre se puede llamar aquello por lo cual el adjectivo se distingue del substantivo. Adjectivo se llama por que siempre se arrima al sustantivo como si quisiessemos llamar arrimado." (p. 60)

Sánchez coloca o adjetivo na categoria dos nomes e sua posição sobre ele se encontra esparsa no livro: o adjetivo se distingue do nome pelo gênero:

"Adjectiva nomina non habent genus, sed terminaciones, ad personas ad genus." (Minerva, $I, 7)$

A Grammaire de Port-Royal também não faz a distinção, que se encontra nos Enciclopedistas:

\footnotetext{
“L'unité d'object qui résulte toujours de l'union de l'Adjectif avec le nom, démontre que l'idée particulière qui constitue la signification individuelle de chaque Adjectif, est vraiment une idée partielle de la nature totale de cet object unique exprimé par le concours des deux parties d'oraison.

Quand je dis, par exemple, loi, je présente à l'esprit un objet unique determiné: j'en présente un autre également unique et déterminé, quand je dis loi évangelique, un autre quand je dis nos lois.

L'idée de loi se trouve pourtant toujours dans ces trois expressions: mais c'est une idée totale dans le premier exemple, et dans les deux autres ce n'est plus qu'une idée partielle qui concourt à former l'idée totale, avec l'autre idée partielle qui constitue la signification propre, ou de l'Adjectif évangelique, dans le seconde exemple ou de l'adjectif nos dans le troisième." (Mot, E. M., II, p. 575)
} 


\subsubsection{O Verbo}

Ao verbo (incluindo o particípio) dedica aproximadamente $45 \%$ de sua obra sem apresentar novidades.

Diferentemente da Gramática Filosófica (por exemplo, as de Soares Barbosa e Moraes e Silva) conceitua verbo como "uma palavra que significa ação, que alguém pratica ou recebe”. (p. 33)

Conjuga os auxiliares e os regulares, dizendo serem três as conjugações; afirma, porém, haver "uma quarta conjugação dos verbos acabados em or, que é só do verbo irregular por e de seus compostos, v. g.: compor, despor, propor, repor, suppor, etc.”. (p. 41)

Isto é o que dizia também Moraes e Silva (1813):

\footnotetext{
"Os verbos em or antigamente tinhão o infinito em er, e erão irregulares da $2^{\mathrm{a}}$ conjugação, porque diziam Poer, Compoer, Propoer, etc.; agora fiz delles uma $4^{a}$ conjugação, ou exemplar de Por, e seus derivados que como elle se conjugão”. (p. XL - grifos meus)
}

\subsubsection{O Pronome}

O pronome é brevemente estudado: dedica-lhe somente uma página:

"Pronome é uma palavra, da qual se usa pelo nome." (p. 30)

É a mesma conceituação que se encontra em Reis Lobato:

\footnotetext{
"Pronome he aquelle que na oração se poem em lugar de outro nome, como quando digo: Pedro estuda Grammatica, e o mesmo ha de estudar Rhetorica."
}

Nas primeiras classificações das partes da oração, o pronome não se distinguia do artigo. Apolônio Díscolo dizia que o pronome designava objetos cuja qualidade se expressava indiretamente.

Dos latinos, Prisciano se referia somente aos pessoais: 
FÁVERO, Leonor Lopes. Breve compendio de grammatica portugueza - Frei Joaquim do Amor Divino Caneca.

"pars orationis quae pro nomine proprio uniuscuiusque accipitur, personasque finitas recipit."

Gramáticos posteriores, como Nebrija (p. 72) se limitaram a copiar a conceituação de Prisciano.

Parả Sánchez, o pronome não é uma das partes da oração, e das várias razões apresentadas para justificar seu ponto de vista, destaco:

a) É impossível definir o pronome; se houvesse diferença entre nome e pronome, seria possível especificá-la na definição.

b) Os aristotélicos dizem que "in voce nominis pronomina etiam includi”.

c) O pronome não substitui o nome, nem o comum, nem o próprio, "Quomodo possunt poni 'pro nomine', si illis significamus res non habentes nomina, aut ea quorum nomen ignoramus? Imo res omnes, antequem nomen haberent, vocabantur 'hoc' vel 'illud'. Como diz Garcia (1960, p. 77), "se ve que el Brocense non tuvo en cuenta las definiciones de los modistas medievales".

d) Os pronomes não distinguem as pessoas gramaticais, pois estas estão nos verbos.

e) Não é possível aceitar-se a definição de Donato porque é ridícula e, além do mais, sua definição de nome inclui também o pronome:

"Pronomen est pars orationis quae pro nomine posita, tantum que paene significant personam que interdum recipit." (Donato, Ars maior, in Donzé, 1970, p. 70)

A Grammaire de Port-Royal e La Logique seguem na linha de Donato, afirmando: "L'usage des Pronoms est de tenir la place des nomes et de donner moyen
d'en etudier la répetition." (Logique, p. 145)

E com estes ficam Reis Lobato e Frei Caneca. 
O pronome pode ser pessoal, possessivo, recíproco, relativo, interrogativo, demonstrativo e indefinido.

\subsection{Parte - Ortografia}

Dedica esta parte ao escrever certo:

"Orthographia é a segunda parte da grammatica, que ensina a escrever com perfeição.” (p. 50)

Apresenta as "duas ordens de caracteres": letras e pausas, dizendo serem as letras, vogais e consoantes e, conforme critérios adotados no artigo "Articulação" da Encyclopédie e seguidos por Soares Barbosa, por exemplo; as vogais vêm primeiro e as consoantes, depois, pois uma ortografia "razoada" exige um alfabeto cuja ordem reflita a classificação dos sons.

Esta segunda parte só desperta algum interesse nas Notas (p. 61-2) quando, como já o haviam feito Beauzée para o francês e Soares Barbosa para o português, se esforça por mostrar que a escritura deve se adaptar ao inventário fonético do português e que o sistema gráfico deve representar os sons e os acentos da língua. Não chega a apresentar, como Verney e Soares Barbosa, uma "ortografia da pronunciação”, mas endossa a posição deste último, citando-o: "Escrevam-se as palavras com tantas lettras, quantas bastem para a pronunciação". (p. 62)

Diz ainda:

"O alphabeto português é muito imperfeito, visto que para formar umas syllabas tem lettras de mais, e para formar outras falta-lhe lettras: porque adoptaram os homens alguns erros que communicaram a posteridade, e que já estão irremediáveis. Esses erros foram habituarem-nos desde a nossa infancia a pronunciar alguma lettras com sons differentes dos sons naturaes, v. g.: a lettra $c$ com som de $k$ ou de $q$; a lettra $g$ com som de $j$; a lettra $s$ com som de $z$; as lettras $c h$ com som de $q$ ou de $x$, as lettras ph com som de $f$." 
FÁVERO, Leonor Lopes. Breve compendio de grammatica portugueza - Frei Joaquim do Amor Divino Caneca.

\subsection{Parte - Prosódia}

Nesta breve terceira parte (uma página e meia), não há nada digno de nota. Diz somente que "ler é pronunciar as vozes representadas pelas lettras com as pausas, accentos e figuras". Como se pode observar, distingue aqui, claramente, letras de vozes. Apresenta a seguir as figuras "por acrescentamento de lettras, por diminuição, por suppressão, por separação, por mudança, por transposição, por contracção e por dilatação”. (p. 52)

Em nota diz haver "duas ordens de figuras grammaticaes, a saber: figuras de dicção e figuras de syntaxe" e figura de diç̧ão é "a alteração das palavras, como se vê na ortographia”. (p. 62) (esta é também a posição de Reis Lobato - 1770). São as figuras que denominamos metaplasmos: prótese, epêntese, aférese, síncope, apócope, etc.

\subsection{Parte - Sintare}

Enquanto dedica à etimologia nove lições, à sintaxe são dedicadas três (XII a XIV).

“[...] a sintaxe é o fim da gramática, logo não é parte dela.” (Minerva, 1, 2, p. 48)

Não apresenta nada de novo, repetindo os que o antecederam (como já disse, a obra tinha por finalidade ensinar à religiosa do convento do Desterro, na Bahia).

Como na Minerva de Sánchez, na Grammaire de Port-Royal e em Reis Lobato, Moraes e Silva e Soares Barbosa, divide a sintaxe em simples e figurada:

"A simples ou natural é a recta composição segundo as regras estabelecidas."

Esta conceituação permite sua divisão entre sintaxe de concordância e de regência. Não menciona a de colocação. 
A sintaxe de concordância vai mostrar a relação de identidade entre as partes e a de regência, a de determinação: "é o poder que uma parte ou oração tem sobre a outra", e oração "é uma reunião de palavras, pela qual exprimimos os nossos pensamentos".

Examina a concordância do sujeito com o verbo, do atributo com o sujeito e entre o adjetivo, pronome e particípio e o substantivo; entre as orações parciais e totais e as subordinadas e a principal.

Na sintaxe de regência diz que há partes regentes (verbo, adjetivo e preposição) e partes regidas. Diferentemente de Reis Lobato e Soares Barbosa inclui o verbo como regente; Soares Barbosa incluíra nos adjetivos o verbo adjetivo. Como os gramáticos anteriores diz serem quatro os complementos: objetivo, terminativo, restritivo e circunstancial.

Não adota, como consequiência de seguir os partidários da gramática filosófica (Soares Barbosa é seu grande inspirador), para os quais a oração é a unidade de análise, a distinção da retórica clássica entre "figurae in verbis singulis" e "figurae in verbis coniunctio", isto é, desvios produzidos nos limites da palavra e os produzidos nos limites da oração (distinção comum entre os gramáticos, como Nebrija).

Na sintaxe figurada, ou regência irregular, distingue três figuras principais: hipérbato, elipse e pleonasmo. É a classificação de Sánchez, que inclui também a silepse, uma espécie de elipse, colocada por Frei Caneca como uma subdivisão da mesma.

A elipse, do mesmo modo que para Argote e Soares Barbosa, não tem mais a mesma função nem a mesma valorização que tinha com Sánchez (essa é também a posição dos Enciclopedistas).

\section{CONCLUSÃO}

A gramática de Frei Caneca pouco ou nada apresenta de novo, limitando-se a seguir os que o antecederam, inserindo-se na voga 
FÁVERO, Leonor Lopes. Breve compendio de grammatica portugueza - Frei Joaquim do Amor Divino Caneca.

das gramáticas filosóficas que marca toda a primeira metade do século XIX, mas tem o mérito de ser uma gramática pedagógica, escrita em linguagem fácil e acessível.

\section{BIBLIOGRAFIA}

ARGOTE, J. C. de (1721) Regras da lingua portugueza, espelho da lingua latina. Lisboa, Officina de Mathias Pereira da Silva

ARNAULD, A.; LANCELOT, C. (1969) Grammaire générale et raisonnée. Paris, Republications Paulet. [A $1^{\text {a }}$ edição é de 1660.]

.; NICOLE, P. (1970) La logique ou l'art de penser. Paris, Flammarion. [A $1^{\mathrm{a}}$ edição é de 1662.]

BARROS, J. de (1971) Gramatica da lingua portuguesa. Cartinha, gramatica, dialogo em louvor da nossa linguagem e diálogo da viciosa vergonha - Reprodução fac-similada. Leitura, Introdução e Anotações por Maria Leonor Carvalhão Buescu. Lisboa, Faculdade de Letras da Universidade de Lisboa.

BARBOSA, J. S. (1875) Grammatica philosophica da lingua portugueza. 6. ed. Lisboa, Typographia da Academia Real das Sciencias. [A $1^{\text {a }}$ edição é de 1823.]

BERNARDES, D. A. de M. (1997) Pacto social e constitucionalismo em Frei Caneca. Revista de Estudos Avançados. Universidade de São Paulo, vol. II (29), p. 155-168.

CANECA, J. do A. D. (1875) Breve compendio de grammatica portugueza. Recife, Typographia Mercantil, edição póstuma.

DONZÉ, R. (1970) La gramatica general y razoada de Port-Royal. Buenos Aires, Eudeba. [A edição francesa é de 1967.]

Encyclopédie Méthodique: grammaire et littérature. Editeé par Beauzée et Marmontel. 17821786. Paris.

FÁVERO, L. L. (1996) As concepções lingüísticas no século XVIII - a Gramática Portuguesa. Campinas, Editora da UNICAMP.

GARCIA, C. (1960) Contribuición a la historia de los conceptos gramaticales. Madrid, Revista de Filologia Española.

MORAES E SILVA, A. de (1813) Diccionario da lingua portugueza "Epitome da Grammatica Portugueza". 2. ed. Lisboa, Typographia Lacerdina.

NEBRIJA, A. de (1946) Gramática Castellana, ed. de R. Galindo e L. Ortiz. Madrid, Muñoz. [A $1^{\text {a }}$ edição é de 1492.$]$

REIS LOBATO, A. S. dos (1770) Arte da Grammatica da lingua portugueza. Lisboa, Regia Officina Typographia. 
Filologia e Lingüística Portuguesa, n. 3, p. 89-103, 1999.

SÁNCHEZ de las BROZAS, F. (1714) Minerva seu de latinae linguae causis et elegantia. Amsterdã.

SWIGGERS, P. (1984) Les conceptions linguistiques des encyclopédistes. Heidelberg, Verlag.

ABSTRACT: This grammar, unknown in these days, belongs to the group of the philosophical grammars published in Brazil in the first half of the XIX century. It has the advantage of being one of the first - probably the first - pedagogical grammar written by a Brazilian author.

Keywords: history of linguistic ideas, general and philosophical grammar, pedagogical grammar. 